\title{
Paideusis
}

\section{Implementing Mindfulness: Practice as the Home of Understanding}

\section{Donald L. Nelson}

Volume 20, Number 2, 2012

Contemplative Practice, Education, and Socio-Political Transformation (Part One)

URI: https://id.erudit.org/iderudit/1071826ar

DOI: https://doi.org/10.7202/1071826ar

See table of contents

Publisher(s)

Canadian Philosophy of Education Society

ISSN

0838-4517 (print)

1916-0348 (digital)

Explore this journal

Cite this article

Nelson, D. (2012). Implementing Mindfulness: Practice as the Home of Understanding. Paideusis, 20(2), 4-14. https://doi.org/10.7202/1071826ar
Article abstract

The practice of mindfulness is a contemplative practice that has been implemented in educational settings as well as in various models of treatment for stress and other conditions. This paper examines how Western scientific psychology has participated in this implementation and the dangers to the practice and concepts of mindfulness inherent in shifting a practice from the cultural and philosophic ground in which it developed to another ground and another discourse. Some caveats for implementing contemplative practices are considered. (c) Donald L. Nelson, 2012

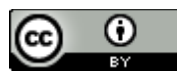

This document is protected by copyright law. Use of the services of Érudit (including reproduction) is subject to its terms and conditions, which can be viewed online.

https://apropos.erudit.org/en/users/policy-on-use/ 
Paideusis, Volume 20 (2012), No. 2, pp. 4-14

\title{
Implementing Mindfulness: Practice as the Home of Understanding
}

\author{
DONALD L. NELSON \\ Simon Fraser University, Burnaby, British Columbia, Canada
}

The practice of mindfulness is a contemplative practice that is being implemented in educational settings as well as in various models of treatment for stress and other conditions. This paper examines how Western scientific psychology has participated in this implementation and the possible dangers to the practice and concepts of mindfulness inherent in shifting a practice from the cultural and philosophic ground in which it developed to another ground and another discourse. Some caveats for implementing contemplative practices are considered.

\section{Implementing Mindfulness Within a Western Paradigm}

The West has developed an interest in the effects of meditation training on the brain, chronicled in part in Goleman (2003), and as meditation based treatment programs are developed and examined, it has become apparent that meditation has remarkable associations with compassion, composure, behaviour, and self awareness. A prominent example is Kabat-Zinn's (1990) Mindfulness Based Stress Reduction program. Meditation based programs have spread to various institutions and schools to help meet the challenges they face. In Buddhist traditions, when mindfulness is practiced seriously, it puts us as practitioners in touch with our experience of the moment, as well as our responses to that experience, in such a way that we will perceive situations as they really are without the unconscious filter of habituated interpretation. Such an outcome would be a valuable part of living fully: first, as we increasingly become aware of our habituated responses to life, and second as our common tendency to see situations only within our usual interpretation is replaced by an awareness of our constantly changing responses to the moment as it is.

The documented beneficial outcomes of developing mindfulness have led researchers to assess the degree to which participants in studies are learning to become more mindful—mindfulness having been identified as the active ingredient, as it were, of these programs. ${ }^{1}$ This research has been primarily conducted within an empirical model assessing the effectiveness of the program and the degree to which the effects of the intervention correlate with increases in mindfulness. There is, therefore, a need to identify, conceptualize, and quantify mindfulness. However, this process of development, implementation, and assessment is filled with conceptual pitfalls. In this paper, I will examine some of

\footnotetext{
1 See Baer, Smith, Hopkins, Krietemeyer, and Toney (2006) for a study that uses empirical analysis of measurement instruments to define and operationalize mindfulness while acknowledging at the same time the increasing evidence that mindfulness is efficacious in some psychological treatments.

(C) Copyright 2012. The author, Donald Nelson, assigns to Paideusis the right of first publication and educational and non-profit institutions a non-exclusive license to use this document for personal use and in courses of instruction provided that the article is used in full and this copyright statement is reproduced. Any other usage is probibited without the express permission of the author.
} 
the difficulties and possible distortions of our understanding of vipassana or mindfulness meditation ${ }^{2}$ when the study of the practice abstracts what is done from the complexity of the tradition in which it is at home. It is important that the effectiveness of mindfulness practice not be lost in the process of scientifically assessing, or even describing these specific programs and implementations of mindfulness practice.

A specific kind of abstraction occurs as a result of this scientific process of conceptualization. Western researchers and teachers of mindfulness themselves have more or less experience of meditation and the traditions from which it is drawn. While many of the originators of the programs that have been examined by scientific research are meditators with great experience within a Buddhist tradition of practice, some are not. In addition, when programs are implemented on a wider scale, they may of necessity rely on teachers with little grounding in the traditions that are home to the practice of mindfulness. There is a difference between talking about a concept seen from "outside" and talking about experience grounded in practice. The concept is contained in language, while the experience is contained in a person.

This point is of particular importance when talking about mindfulness meditation. One continually encounters this sort of reminder in Buddhist literature: "You learn what meditation is all about and where it leads only through direct experience of the thing itself' (Gunaratana, 2002, p. 110). Indeed, in Buddhism, in the reported words of the Buddha, students have been told to question every statement, compare it to their own experience to test whether it is accurate and useful. ${ }^{3}$ The common Buddhist simile of the finger and moon says a lot about the nature of the non-dogmatic relationship expected between a Buddhist and the teachings of Buddha: a teacher may use his or her finger to point to the moon, but the student should never mistake the finger for the moon. The Dharma (teaching) is like a finger and understanding is like the moon.

Another sort of abstraction occurs in the process of reconceiving mindfulness practice as a modern, science-based practice. With mindfulness in particular, in the case of secular public schools, a scientific re-conceptualization of the practice has a particular use. It serves to secularize the practice of meditation by positioning it outside of religious tradition. Mindfulness is a concept closely associated with Buddhism and so is often seen as part of that religion even though Buddhism is non-theist and only in some of its forms devotional in any religious sense. However, to employ Buddhist practices in public schools would be difficult or impossible because they would be seen as "teaching religion." That is one reason why many studies of mindfulness begin by arguing that mindfulness is a human capacity common to many religious, devotional, or contemplative traditions. See Siegel (2007, pp. 8-9) for an example of how this characteristic view is presented. Taking these separate practices, calling them all mindfulness practices, and then looking for commonalities has the effect of secularizing the concept and making it non-religious, or at least of no particular religious origin-thereby rendering it acceptable in schools that could not or would not promote a specific religious practice in their curriculum. ${ }^{4}$

Several questions result from these observations. First, when programs using mindfulness practices are based solely on what empirical research identifies as mindfulness, will those programs be

\footnotetext{
${ }^{2}$ Because of different names given to this meditation practice, confusion can easily result. Vipassana meditation is usually called 'mindfulness meditation, or sometimes insight mediation, in the English speaking West. It is prominent in Theravada Buddhism, but is also present in other schools. It begins with a focus on the breath and, as concentration and mindfulness develop, expands attention to include experience more widely.

3 "Precepts in Buddhism are not imposed by some outside authority. They arise from our own insight based on the practice of mindfulness. To be attached to the form without understanding the essence is to fall into what Buddhism calls attachment to rules" (Hahn, 1995, p. 27).

${ }^{4}$ Science is not alone in "de-discriminating" differences between religions. Stephen Prothero (2010) has the idea that all religions share essentially the same body of ideas or practice. This idea not only minimizes differences that are essential to understanding individual religions, but may also lead to attitudes that other believers should be "just like us."
} 
able to transmit what mindfulness actually is? More specifically we might ask, is the understanding of mindfulness as a mental exercise or skill sufficient to understand the full practice of mindfulness and then to teach it to others? My fear would be that without proper care taken to contextualize the practice within the tradition in which it has grown, so-called mindfulness programs could lose touch with the practice that has suggested such beneficial and transformative outcomes.

The remainder of this paper will contrast two presentations of mindfulness: that of Bhante Henepola Gunaratana (2002), writing about vipassana meditation within the Theravada school of Buddhism, and that of professor of psychiatry Daniel Siegel (2007), whom I will use as a representative of the scientific conception of mindfulness. Within the confines of this paper, I do not suppose that I am doing full justice to the complexity of either of these examples. My intention is only to point out that on the face of it, there are significant differences in the way mindfulness is talked about and that these differences could point towards two conceptions of mindfulness that are different in important ways. Having looked at these two views, I will go on to contrast key differences in them and speculate what might be lost if teachers of mindfulness and mindful education were to use only the scientific formulation of the practices in their work.

\section{A Living Tradition}

After the death of the historical Gautama Buddha, Buddhism was transmitted through an oral tradition. Then, words that had been heard and passed on were written down and eventually added to, creating texts that have been translated, codified, and debated. One response to this sort of debate was chronicled in the Record of Master Linji, stories of a founder of the Zen school of Buddhism. Master Linji recoiled from what he perceived as the seeking for advancement through the intellectual and academic debate of the dharma. He started his own school that emphasized each student's ability to wake up to understanding immediately through direct breakthroughs. His signature style of teaching emphasized this challenge and was focused more on kicking away the crutch of dharma talk than on discussion of its fine points. ${ }^{5}$

In all the schools of Buddhism, however, there is a core focus on the "Four Noble Truths" of Buddhist philosophy: Life contains suffering ${ }^{6}$; this suffering is caused by grasping onto an ever changing reality and trying to freeze it in certain ways; all this can change; and the way to change it is through following the Eightfold Path. This path involves clearing up one's way of living, developing one's mind, and seeing through appearances to an underlying reality where there is no grasping or avoiding of what is and, when equanimity is attained, the cessation of suffering. The practices of the schools of Buddhism, whether in the vipassana meditation of the Theravadan school or the "just sitting" of Zen, serve two purposes: (1) individuals practice to find freedom from suffering and develop compassion that is individually and collectively beneficial; and (2) to experience through practice, support and, in a loose sense, verification of the claims of the dharma or teachings.

One vehicle for the transformation that leads to the end of suffering is the practice of meditation, the oldest form being vipassana. ${ }^{7}$ This meditation teaching begins with focusing attention on the breath and it is the meditation teaching that has become the focus of much interest in Western psychology. See Siegel (2007) and Brown, Warren, Richard, and Creswell (2007) for overviews of this interest.

\footnotetext{
${ }^{5}$ For a more thorough overview of this history see Thich Nhat Hanh (2007).

6 "Suffering" is the usual translation of the Pali word "dDukkha." Dukkha can also be translated as an unsatisfactory or uncomfortable condition, like that of a wheel gone out of round, which is different from a painful condition as generally implied by the word "suffering." Here I have chosen to follow the usual translation.

${ }^{7}$ Said to have been taught by the Buddha himself (Gunaratana, 2002, p. 31).
} 
Advanced meditators examined in labs revealed abilities to Western science that suggested applications to problems such as stress reduction, psychotherapy, and some learning and behaviour difficulties. Western studies have focused on the brain state of mindful awareness practitioners in the hope that beneficial effects associated with it can be used in psychotherapy and schooling (Siegel 2007, p. 6.). The assumption in the scientific implementation model has been that the focus on brain states and empirical observation will capture the effective aspects of the practice. ${ }^{8}$

\section{The Mindfulness Construct and Mindfulness}

The first step in the scientific evaluation of the various mindfulness interventions is often the creation of a mindfulness construct that can be used to measure the degree to which mindfulness is developed in the subjects of the intervention. This process of conceptualizing, standardizing, and theorizing that is an inherent part of this scientific process is just beginning with regards to mindfulness and some of the difficulties of this process have been recognized (Siegel, 2007; Brown et al., 2007). The forming of a "mindfulness construct" is one way that differing conceptualizations or "pictures" of mindfulness have been highlighted (Brown et al., 2007):

The Buddhist scholarly literature presents a detailed picture of the nature of mindfulness. However, that literature's characterization of mindfulness has not been clearly translated into contemporary research psychology. (p. 214)

The purpose of "picturing" within the two great traditions is different: one is religious (in some sense) and sees the practice of mindfulness as part of the path to liberation from suffering; the other is scientific, using the word "mindfulness" to explore and explain changes in behaviour and brain functioning. Mindfulness in each tradition is connected through related but distinct practices.

It should be noticed that just the use of the word "mindfulness" in educational practices can lead to confusion that comes from using a word taken from one practice to refer to a different practice done in a different context. The term "mindfulness" is used in different models of education; for example, E. J. Langer's work on mindful learning. ${ }^{9}$ Langer and Moldoveanu (2000) have emphasized one aspect of a general notion of mindfulness, saying it is the "process of drawing novel distinctions", and have developed this construct in their work in education. The focus in this work is on paying attention in specific ways while learning, making what is taught conditional or open in nature, and keeping what is being taught conditional and fluid rather than absolute and frozen. Thus, Siegel (2007, p. 8), to distinguish his sense of mindfulness from Langer's, identifies two kinds of mindfulness: "mindful learning" on the one hand, and "reflective mindfulness", "mindful awareness", and just "mindfulness" when referring to interventions that use meditation-based strategies. These last three terms he takes to be synonymous. But are there really two, or many, kinds of mindfulness? Or does Siegel create two conceptions of mindfulness to accommodate a specific model of mindfulness that fits a mindfulness construct as currently defined? One might argue that the application of understandings discovered during mindfulness practice confirms an understanding of what is learned as tentative, open to change and revision, and so on. If so, there are not two kinds of mindfulness, but one that is working in different ways.

I would argue that these different ways of interpreting mindfulness result not simply because of different definitions of mindfulness. They result from differences between the scientific mindfulness

\footnotetext{
${ }^{8}$ Reviewers of this article remind me correctly that this assumption is not generalizable to all neuro-scientific studies of meditation. The focus here is really on programs that, intentionally or not, restrict themselves to an understanding of mindfulness based only on science-based evaluation and definition of mindfulness.

${ }^{9}$ See the discussion of this in Siegel (2007, p. 6-8).
} 
construct and mindfulness in its home, contemplative traditions. These differences cannot be solved by simply cleaning up terminology. Eleanor Rosch (2007) has developed a similar point: her argument notes that "mindfulness" in Buddhist teaching is part of a system of ideas, one path on an eight fold path towards enlightenment. To focus only on mindfulness is to miss the greater vision of how Buddhist traditions see the impact of meditation and mindfulness on the practitioner. The scientific need to define and measure the effective components of the mindfulness-based therapies, Rosch maintains, potentially occludes this larger context. A possible result is that the thing being measured is not the thing having the effect: "By now it should be clear to anyone acquainted with the scales [measuring mindfulness] that none of them is measuring either mindfulness in the narrow Buddhist sense or enlightened awareness in its broader sense" (Rosch, 2007, p. 262).

Mindfulness is only one aspect of certain kinds of meditation-in vipassana meditation, concentration and mindfulness of the workings of the mind lead to insight, for example. This is another aspect of meditation that has received Western attention for its therapeutic effects in relaxation. Insight has been studied and identified as a source of beneficial effects. ${ }^{10}$ Science, by its nature, seeks to isolate and identify what is causing what, and this tendency may miss important interconnections or synergistic relationships. In vipassana meditation, relaxation may be one outcome of practice, but it is not the goal of practice. Meditation may result in a deep state of relaxation (jhana), but the goal is insight or as Gunaratana (2002) puts it: "Vipassana seeks another goal: awareness" (p. 19), and awareness is one path on the road to liberation. Focusing on relaxation is an example of how one of the effects of meditation can be separated from the practice of meditation for examination, with the effect of leaving meditation in its full experience unexamined.

The operation of this medical paradigm is straightforward. An illness is identified together with interventions that seem to have some impact on it. The interventions are analyzed in search of the active ingredient having the desired effect on the disease. The analysis can be purely empirical, as "we don't know why chewing the bark of that tree makes headaches go away, but it does," but more often employs some further scientific method and theory: "Something in that bark must either affect the pain center of the brain or stop the transmission of signals along the nerves." The ingredient is identified and its effect measured, compared to others, and dosages determined through trials, and then the cure is implemented. This is a simple way of describing the process, ignoring complexities all along the way. The process has resulted in many good things, like antibiotics, and many lives have been saved.

The pull of this paradigm is very strong. It offers a cure or an intervention that has impact on the disease. The idea that there is some form of meditative awareness that can be prescribed to students to solve their learning or behavioural problems has great attraction. Work is being done along just these lines: identifying the impacts of meditation, analyzing meditation to identify the aspects of it that have the greatest impact, theorizing what connections are being made in the brain, devising and evaluating interventions for schools, and so on.

Two possibly conflicting purposes are served by, on the one hand, looking for a prescription of meditation based on an analysis of brain function and behavioural change or, on the other hand, distinguishing between the practices, methods, and goals of different traditional schools of Buddhism. The first endeavor seeks to locate the effect of mindfulness in the secular or at least nondenominational brain and the practices that develop the capacity for better mental health. The second seeks to maintain the practices within the ideas and traditions of Buddhism where mindfulness is part of a path to liberation in order to preserve what has been developed over 2500 years of tradition, possibly to maintain ownership of the practice, and so on. These conflicting purposes arise for a number of reasons, some malicious, competitive, and personal, and some concerned with accuracy, truth, and preservation of a line of transmission. They come about as a result of the lens that is used to view mindfulness and the way in which the differing perspectives make sense of how it should be best

${ }^{10}$ For an example of this study and its early positioning as study of a mental state rather than a religious or philosophical position see Herbert Benson (1983). 
understood, developed, and made available for use. The program evaluator, using the lens of scientific method, seeks to make the benefits of mindfulness understood and available, just as Buddhist meditation teachers, using the understandings of meditation and humanity developed within their tradition, seek to help practitioners along the road to liberation.

\section{Differences Between Buddhist and Scientific Mindfulness}

The general argument to this point suggests how a Buddhist view and the scientific view of mindful meditation would differ. Both views see the potential of mindfulness to bring about positive changesthough those changes may be conceived quite differently-that come largely from the differences between mindful attention and a common sort of attention and inattention. For one, mindfulness improves individuals' ability to understand their lives and so enables them to better moderate their emotional responses in life. For the other, mindfulness is part of a path to liberation from suffering. Mindfulness allows people to live more deeply in the present moment often with more complete awareness of physical sensations and their own engagement in interpreting their experience.

Similarities are to be expected since science has studied people trained in the Buddhist tradition as experimental subjects. In addition, many of the programs for stress reduction or pain control employ traditionally trained teachers. Because of this, the language used to describe mindfulness shares similarities. The differences arise when mindfulness is conceptualized for study, and the differences deepen as these concepts are used to define what mindfulness is and how it will be studied and practiced. In the Buddhist view, mindfulness is a path that shows and verifies certain truths of existence. It is the direct, pre-conceptual experience of these truths that leads towards freedom, happiness, and contentment. Understanding the experience is not the same as a description or picture of a brain state, even though understanding will have a brain state associated with it.

A further example of this difference can be seen in Siegel's (2007) view that mindfulness attunes one with one's own intentions or "primary self." "He hypothesizes that with mindfulness, one is using neural circuitry that allows us to attune to others and to attune to a primary self within oneself. It is not an exaggeration, given the extent to which Siegel says most of us are out of touch with this primary self, to say that mindfulness allows us to discover this primary self. This discovery is very different from the discovery of selflessness that is talked about in Buddhist literature. ${ }^{12}$ In the Buddhist view, there is no primary self but rather a "flowing vortex of thought, feeling, and sensation" (Gunaratana, 2002, p. 37). There is no separate or essential self with which to attune.

One might argue that Siegel means by "primary self" just that vortex of thoughts and so on. That is, one might claim that Siegel is talking about the same thing as Buddhism but in another way-a perhaps misleading way-for the associations connected with "primary self" are different than those most people would have with "not-self" or "no-self" (if most Westerners have any associations with these two terms). On the other hand, Gunaratana (2002) writes that it is the realization of the illusion of a separate, fixed self, and the mistake of hanging on to that self so desperately, that is the key insight that leads to liberation and more openness:

If you explode that one concept [of " $m$ " as distinct from everything else], your whole universe changes... The "I" concept is a process. It is something we are constantly doing. With vipassana we learn to see that we are doing it, when we are doing it, and how we are doing it. Then that mindset moves and fades away, like a cloud passing through a clear sky. We are left in a state where we can decide to do it or not, whichever seems appropriate to the situation. The compulsiveness is

\footnotetext{
11 See also: "Mindful awareness promotes neural integration" (p. 320) and, "We share our 'ipseitious self with each other, that grounded core essence beneath our adaptations, beliefs, and memories" (p. 321).

12 See Thich Nhat Hanh (1995, pp. 38-40) or Gunaratana (2002, pp. 37-38).
} 
gone: now we have a choice. (pp. 37-38)

It is, in Buddhism, insights like this one that have the therapeutic effect. Gunaratana (2002) explains:

They lead to a total transformation of your life. Every second of your existence thereafter is changed. The meditator who pushes all the way down this track achieves perfect mental health, a pure love of all that lives, and complete cessation of suffering. (p. 38)

If this is taken at face value, then the idea of a primary self is more than misleading: it contradicts the Buddhist explanation for the salutary effects that are desired. Mindful awareness is more than momentto-moment awareness, but is it an awareness of an "essential self," something that one might have to hang on to because it is "essential," or is it awareness that there is no essential or timeless self, but rather a self that is changing from moment to moment, and it is that awareness of "no self" that itself constitutes part of perfect mental health?13

So here we have two interpretations of what purports to be the same phenomenon or capacity. Neither of these interpretations can be found better than the other through scientific analysis for they take their meaning from the world view or, to be more Wittgensteinian, the pattern of living, in which the interpretation finds its home. Siegel writes from the point of view of a counseling therapist, a view likely to be different than a neuroscientist looking at the brain states of meditation, where finding and attuning to an essential self might be seen as the goal. Gunaratana writes as a Theravadan Buddhist with the goal of helping others attain personal liberation. The result is a description of an aspect of mindfulness that is different between these two approaches.

This difference between these conceptions of mindfulness is not to be solved through science because it is, in effect, the result of a first person point of view explanation of a conscious experience contrasted with a third person point of view explanation of the neurology of experience. ${ }^{14}$ The meditator has a pre-conceptual direct experience that she or he seeks to express in terms that explain the experience and give reasons for such changes in attitudes, behaviour, and understanding that result from it. The neurologist sees these differences and investigates the neurology that supports them, finding characteristic differences in thickness or density of neural connections in the brain. The change in thinking (a phenomenon of first person ontology) is evident in a change in neural pathways (a phenomenon of third person ontology), but the two are in effect the same phenomenon viewed from two different perspectives. It is from the first person view, however, that the work is done in mindfulness practice, and while knowing the other view may be interesting, that knowledge alone does not produce mindfulness, nor does it support an interpretation of what mindfulness is, or how a mindfulness practice can be best described or taught to others. Whether mindfulness practice can best be described as a search for an essential self or not, is a third person point of view question. It may be that someone preferring that description to the Buddhist notion of confirming the experience of noself comes to that preference through being part of a Western form of living that emphasizes the individual self. And it may be that mindful experience actually challenges that way of life.

In any case, just having a correct description of mindfulness is not the same as practicing mindfulness. And in the tradition in which Gunaratana writes, the practice of mindfulness will eventually confirm insights into no-self and impermanence. The following section examines the intentional content said to be supported by practice.

13 This discussion of no-self and primary self emphasizes their contradictory nature. See chapter 14 in Kornfield (1993) for a deeper discussion of self on a spiritual path. His discussion only exists, of course, because both aspects of self are part of the discourse.

${ }^{14}$ I am indebted to John R. Searle's (2004) ideas for this way of looking at this issue. 


\section{Mindfulness as an Intentional State}

If we simplify Siegel's presentation of mindfulness, we see that mindful meditation is an exercise done to reshape and refine neural pathways; that is, the exercise works because the pathways are created or reinforced through the practice. The beliefs that accompany the practice, whether they are some form of Christian contemplation, for example, or Buddhist dharma, are irrelevant to the effect achieved by the shaping of the brain.

We can use a thought experiment to illustrate this conception. Suppose that a key increase in brain activity in a zone of the left prefrontal brain is associated with feelings of happiness, joy, energy, enthusiasm, and alertness, while a corresponding increase in activity in the right prefrontal area is associated with sadness, anxiety, and worry. Brain scans show that highly trained meditators intentionally generating feelings of compassion towards themselves and all sentient beings show a strong shift towards activity in the left area associated with positive states. ${ }^{15}$ Suppose also, a biofeedback device is designed to allow subjects to learn to control this shift to the left by whatever means work for each individual; that is, a person might find that focusing on a mental image of a favourite pet indicates a leftward shift, or another might find that the remembered smell of his father baking a chocolate cake creates the shift. The brain-based look at developing the pathways of positive mood through mental training would say that any of these methods would have the desired effect of strengthening positive moods in the subjects.

These examples are fairly innocuous. But suppose a subject in the biofeedback regime discovered that a leftward shift could be achieved through fantasies of strangling the operator of the machine. Someone working in a purely science based model of meditation would have nothing to object to in this case as what is studied is the pattern of brain activity, not the intentional content that produces the pattern of activity sought. ${ }^{16}$ This is distinctly different than what we find in Gunaratana (2002):

Without loving friendliness, our practice of mindfulness will never successfully break through our craving a rigid sense of self. Mindfulness, in turn is a necessary basis for developing loving friendliness. The two are always developed together. (p. 177)

"Loving friendliness" here is Gunaratana's translation of metta, usually translated as "loving kindness". In short, there is a sense in the Buddhist tradition represented by Gunaratana that the content of the thought, image, or fantasy that develops mindfulness, which has been associated with the shift toward the positive side of the brain matters, and that using thoughts of compassion is part of this tradition of meditation practice. In other words, the intentional content of the practice associated with positive states of mind, is a central part of instruction in the practice.

Are there other understandings, beliefs, or forms of intentional content essential to the practice of mindfulness? Does the intentional content of mindfulness practice matter? For example, does it matter that Buddhist practitioners see one of the insights of mindfulness as the realization that nothing, not even the sense of "I", has a separate essential identity, while Siegel describes an insight of mindfulness as connection with a primary self usually concealed by our beliefs about who we think we are? It may be that these different ways of speaking each refer to similar experiences, but here I have to acknowledge Wittgenstein's argument against private languages and ask, how would we ever know? The answer to the question whether scientific mindfulness is the same as mindfulness in the Buddhist tradition cannot be answered by saying the observed brain states are similar. It can only be answered

15 The neuroscience regarding the right/left shift and negative/positive mood is taken from Daniel Goleman, (2003) p. 12-13.

${ }^{16}$ As a thought experiment, we can leave aside the possibility in this example that fantasies of another's violent death might not ever, as an empirical finding, produce the pattern of brain activity sought. 
that they seem to be playing the same language game within the same pattern of living.

We would usually not say that the thought, "I am only those things that have gone to making me who I am at this moment and will change in the next moment," is the same thought as "I know who I really am and what I really want." Those thoughts might be part of a personal transformation over time, but still they are not the same. Both thoughts have content, and the content is different. If thoughts (objects of first person point of view) have specific associated brain states (objects of third person point of view) then the associated brain states will be different even if we do not currently have technology to detect differences at this level. However, even if there are no associated brain state differences detectable between these two thoughts, there will be different meanings, interpretations, and implications for actions that might come from them. Therefore, someone practicing mindfulness to discover a primary self is practicing a mind state whose cognitive content is different from someone who discovering that everything is without an unchanging essence or self. The primary-self practice may be useful in some ways, indeed if the primary self is something like "I know what I really want and I am committed to getting it," and takes forms like "I know I really want good grades in school and I'll do what it takes to get them," or "I really want this marriage to work and I'm ready to devote time and attention to make that happen." Their utility and desirability in the context of a psychological intervention is clear. But the brain state view can, on its own, have little to object to about the discovery of this kind of primary self: "I really want to make as many people suffer as I can, and I will devote all my energy to that task."

The Buddhist idea of mindfulness is concerned with the intentional content of mindful insights, believing this content will have a profound impact on the conduct of those practicing mindfulness. This is why instruction in meditation traditionally includes talk about intentions, attitudes, impermanence, and so on. ${ }^{17}$ In addition, meditation training traditionally takes place with people who have made some commitment to observing precepts to guide their behaviour. ${ }^{18}$ In effect, this structure provides a context within which one is helped to focus, interpret, and understand the experience of meditation. For example, take this passage from Gunaratana (2002) referring to the habit of thought of focusing on contrasts between oneself and others:

The meditator's job is to cancel this unskillful habit by examining it thoroughly, and then replacing it with another. Rather than noticing the differences between oneself and others, the meditator trains him or herself to notice the similarities. (p. 42)

The meditator examines thoroughly all that arises in meditation, without pushing away or censoring, but then lets go of whatever arises. In the process, one learns to replace unskillful habits of thought with others that better further the development of compassion and insight. The idea is that there are some thoughts that are less skillful in developing mindfulness leading towards liberation and insight and that there are some habits that are less useful and should not be reinforced through practice is explicit. For example, in order to further the development of mindfulness, a person should develop the habit of noticing ways in which he or she is similar to others, noticing other thoughts, letting them go, and coming to experience them as products of the habit of dualistic thinking, grasping, or aversion. Those thoughts that continue to focus on differences between the meditator's self and others are "unskillful thoughts" insofar as they separate the person from compassion for, and connection with, others. ${ }^{19}$ Simply, the intentional content of the thoughts one has and brings to mindfulness practice do matter and can either further or hinder the development of mindfulness and its benefits.

\footnotetext{
17 Gunaratana (2002) includes all these topics and more.

18 See Thich Nhat Hahn (1993) for a modern expression of these "mindfulness trainings."

19 "An unskilled thought is one connected with greed, hatred, or delusion. These are the thoughts that the mind most easily builds into obsessions. They are unskilful in the sense that they lead you away from the goal of liberation." (Gunaratana 2002, p. 118)
} 
This emphasis on the intentional content of mindfulness, or perhaps more precisely, the insights gained through mindful meditation expressed in the language of Buddhist tradition, is made explicit in Tibetan traditions of Buddhism. There, mindfulness is distinguished from the application of "constant awareness to the actual processes of thought, just observing your mind and the thoughts as they arise," and is instead "the mindfulness of that knowledge, not the monitoring of awareness." "That knowledge" is composed of such things as knowing that some actions spurred by thought and emotion, such as punishing someone who has put obstacles in one's path, would be harmful both to oneself and to the other. The Dalai Lama goes on to say, "Mindfulness is bringing to the present the awareness of things that you have learned"(as cited in Ekman, 2008, p. 55). This "mindfulness of lessons learned" is a different emphasis than the mindfulness of the present moment, or the mindfulness of the participation of one's mind in perception, and is an example of the complexity of the notions of mindfulness within Buddhist tradition.

This is not to say that mindfulness practice is thinking certain thoughts. Mindfulness in Buddhist traditions is about noticing thoughts and their origins in grasping or aversion rather than being caught up and identifying with them. One does not stop thinking or force the mind into a quiet state-at least in vipassana meditation. There are other forms of meditation in Buddhist traditions that are all about single-focused attention or concentration. The ability to stay with mindfulness requires trained concentration, but being mindful is not simply having the ability to concentrate. ${ }^{20} \mathrm{It}$ is taking up a point of view from which one can have thoughts but not be caught up in thinking them "mindlessly" or identify them as part of your very self. All this description and conceptualization of mindfulness is on the edge of logic. As Gunaratana (2002) notes: "There is a difference between being aware of a thought and thinking a thought. That difference is very subtle. It is primarily a matter of feeling or texture" ( $\mathrm{p}$. 70). These sorts of distinctions are one reason why mindfulness must be practiced rather than understood through description.

I do hope that the conclusion that in Buddhist traditions some understandings are considered to be essential to developing the ability to be mindful in meditation and in life has been made, and therefore a program of mindfulness practice cannot be based solely on a scientific understanding of mindfulness. Earlier, I asked whether the findings of science alone could be used to identify what mindfulness is and how it should be used and taught. The answer I have advanced is 'no'. Another question is, can the findings of science help individuals to better understand and incorporate mindfulness in their lives. The answer here is 'yes'. If nothing else, recent scientific study of meditators has shown clearly that meditation can have profound impacts on those who practice, impacts that are seen in how their brains function. Such studies can provide an impetus to take up the practice and a view of the impact of the practice on the brain. Both of these uses can be helpful: a skillful teacher of mindfulness must be able to talk about it in ways that fit the traditional home of the concept while at the same time using words that successfully communicate with those not raised in that tradition. This is a tall order, but it is an order central to all good teaching. All teachers take a subject or a practice, such as the practice of the scientific method, and introduce it to students for whom it is outside their experience. To do so successfully, such teachers bring their experience together with their understanding of their students in order to offer tips, examples, and whatever else they can imagine that will help students to see in a new way. Those familiar only with the science of mindfulness run the risk of losing touch with the foundations of the concept with which they are working.

A few other caveats arise from this line of thinking. The first-beware of any move from the use of a traditional contemplative practice into the scientific study of its effectiveness, particularly if the first move is to abstract the practice from its traditional home. The danger of making it a medicine without beliefs or values attached is high, for contemplative life impacts all aspects of living, thinking, feeling, and believing. While contemplation and meditation may have evolved over time in different traditions,

${ }^{20}$ See Gunaratana (2002), Chapter 14, for a full discussion of the synergistic relationship between concentration and mindfulness. 
that evolution is a different process than scientific abstraction. Second-within the philosophical category of "contemplative practices", we must beware of lumping together practices that are in many ways distinct. To suppose that all contemplative practices have a common goal and a common purpose may well be to perform a dangerous kind of abstraction of our own.

The practice of vipassana or mindfulness meditation as traditionally conceived offers the possibility of both insight and wisdom. These outcomes exist because the practice does more than create a different brain state for a prescribed length of time. It offers an experiential course of discovery that can affect behavior and thinking, emotion and perception. Its usefulness can only be preserved through viewing mindfulness as a practice that lives within a complex and evolving historical and cultural tradition kept alive by careful transmission from teacher to student.

\section{References}

Baer, R. A., Smith, G. T., Hopkins, J., Krietemeyer, J., \& Toney, L. (2006). Using self-report assessment methods to explore facets of mindfulness. Assessment, 13, 27-45.

Benson, H. (1983). The relaxation response: Its subjective and objective historical precedents and physiology. Trends in Neurosciences, 6(7), 281-284.

Brown, K., Warren, R., Richard, M., \& Creswell, J. D. (2007). Mindfulness: Theoretical foundations and evidence for its salutary effects. Psychological Inquiry, 18(4), 211-237.

Ekman, P. (Ed.). (2008). Emotional awareness: Overcoming the obstacles to psychological balance and compassion: $A$ conversation between the Dalai Lama and Paul Ekman, Ph.D. New York: Times Books.

Goleman, D. (2003). Destructive emotions: A scientific dialogue with the Dalai Lama. New York: Bantam Dell.

Gunaratana, B. H. (2002). Mindfulness in plain English. Boston: Wisdom Publications.

Kabat-Zinn, J. (1990). Full catastrophe living: Using the wisdom of your body and mind to face stress, pain, and illness. New York: Delta Books.

Kornfield, J. (1993) A path with heart: A guide through the perils and promises of spiritual life. New York: Bantam Books.

Langer, E. J., \& Moldoveanu M. (2000). The construct of mindfulness. Journal of Social Issues, 56(1), 1-9.

Nhat Hahn, T. (1993). For a future to be possible: Commentaries on the five mindfulness trainings. Berkeley: Paralax Press.

Nhat Hahn, T. (1995). Zen keys. New York: Doubleday.

Nhat Hahn, T. (2007). Nothing to do nowhere to go. Berkeley: Parallax Press.

Prothero, S. (2010). God is not one: The eight rival religions that rule the world-and why their differences matter. New York: HarperOne.

Rosch, E. (2007). More than mindfulness: When you have a tiger by the tail, let it eat you. Psychological Inquiry, 18(4), 258-264.

Searle, J. R. (2004). Mind: A brief introduction. New York: Oxford University Press.

Siegel, D. J. (2007). The mindful brain: Reflection and attunement in the cultivation of well-being. New York: W. W. Norton and Co.

Sternberg, R. J. (2000). Images of mindfulness. Journal of Social Issues, 56(1), 11-26.

\section{About the Author}

Donald Nelson is an Adjunct Professor and Adjunct Faculty Associate in the Faculty of Education at Simon Fraser University. He recently retired after years of teaching in public secondary schools. He can be reached atdlnelson@sfu.ca. 